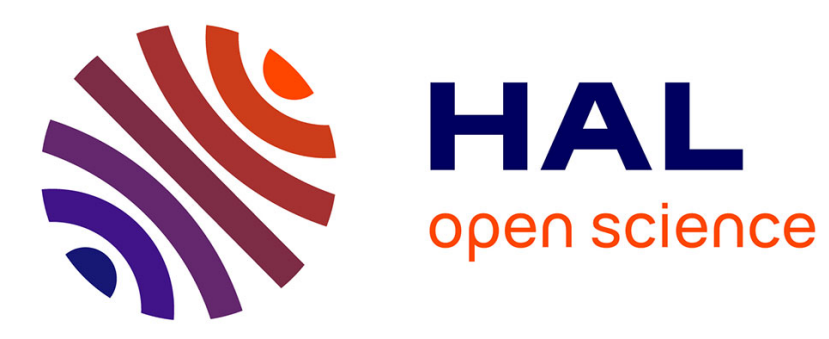

\title{
Study of the Electron Mean Free Path by Ballistic Electron Emission Microscopy
}

C. Girardin, Roland Coratger, Renaud Péchou, François Ajustron, J. Beauvillain

\section{- To cite this version:}

C. Girardin, Roland Coratger, Renaud Péchou, François Ajustron, J. Beauvillain. Study of the Electron Mean Free Path by Ballistic Electron Emission Microscopy. Journal de Physique III, 1996, 6 (5), pp.661-669. 10.1051/jp3:1996148 . jpa-00249483

\section{HAL Id: jpa-00249483 https://hal.science/jpa-00249483}

Submitted on 1 Jan 1996

HAL is a multi-disciplinary open access archive for the deposit and dissemination of scientific research documents, whether they are published or not. The documents may come from teaching and research institutions in France or abroad, or from public or private research centers.
L'archive ouverte pluridisciplinaire HAL, est destinée au dépôt et à la diffusion de documents scientifiques de niveau recherche, publiés ou non, émanant des établissements d'enseignement et de recherche français ou étrangers, des laboratoires publics ou privés. 


\title{
Study of the Electron Mean Free Path by Ballistic Electron Emission Microscopy
}

\author{
C. Girardin (*), R. Coratger, R. Pechou, F. Ajustron and J. Beauvillain \\ Centre d'Elaboration de Matériaux et d'Etudes Structurales-Laboratoire d'Optique \\ Electronique, 29 rue Jeanne Marvig, B.P. 4347, 31055 Toulouse, France
}

(Received 2 October 1995, revised 12 January 1996, accepted 14 February 1996)

PACS.73.40.Ns - Metal-nonmetal contacts

PACS.61.16.d - Electron microscopy and other methods

\begin{abstract}
Ballistic Electron Emission Microscopy allows buried interfaces to be characterized with a subnanometer resolution. Additionnally, the electron mean free path in a thin metal layer can thus be investigated with a good level of accuracy. This paper presents the latest results in this field for an $\mathrm{Au} / \mathrm{n}-\mathrm{Si}$ Schottky diode. A discussion is also proposed to link these results with the still controversial interpretations of BEEM contrasts.
\end{abstract}

Résumé. - La microscopie par émission d'électrons balistiques permet la caractérisation d'interfaces enfouies, avec une résolution inférieure au nanomètre. De plus, le libre parcours moyen des électrons dans une fine couche métallique peut être étudié avec une excellente précision. Cet article présente les dermiers résultats dans ce domaine, pour des diodes Schottky $\mathrm{Au} / \mathrm{n}-\mathrm{Si}$. Une discussion est également proposée pour relier ces résultats aux interprétations, toujours très controversées, des contrastes fournis par les images BEEM.

\section{Introduction}

With the advent of STM in 1981 [1], many interesting applications have been developed. Among them, Ballistic-Electron-Emission-Microscopy (BEEM) was first reported by Kaiser and Bell in $1988[2,3]$.

Whereas STM is particularly well-suited to the observation and characterization of conducting surfaces, buried interfaces may be investigated by BEEM. Indeed, if the sample consists of a metal/semiconductor junction, the electrons emitted by the tip and the energy of which is given by the applied bias voltage $V_{t}$, can be collected in the semiconductor. However, to obtain this, a few conditions have to be met.

Firstly, electron energy must be sufficient to overcome the potential barrier between metal and semiconductor. Secondly, the thickness of the metal film should not exceed the electron mean free path, so that some electrons have a non-zero probability of crossing the overlayer. Finally, electrons should reach the interface plane in an almost normal direction. Indeed, particles arriving at the interface with an angle higher than a critical angle are reflected in the metal layer [4]. Many experiment parameters can be controlled, but the electrons incidence cannot be planned.

$\left(^{*}\right)$ Author for correspondence (Fax: (33) 622579 99)

(C) Les Éditions de Physique 1996 
So far, BEEM has been used to investigate many metal/semiconductor junctions. III-V group semiconductors have already been researched (GaAs $[5,6], \mathrm{GaP}[7,8]$ ) just like II-VI group (CdTe [9,10], ZnSe [11]) and column IV semiconductors (Si [12,13]). Other papers investigate the fundamental interactions of electrons in the metal layer (scattering [14], electron-phonon interaction [15], . ) and the collector $[16,17]$ (ionisation at high energy, defects, ..). The aim of this paper is to study the evolution of the electron mean free path as a function of energy in the 1 V-2 V range. As a reference, the well-known standard gold-silicon metal/semiconductor contact has been chosen.

\section{Experimental Set-Up}

The home-built pocket-size STM used has already been described elsewhere [18]. Two additionnal electronic set-ups allow for controlled variations of the bias voltage during an experiment and simultaneous acquisition of ballistic currents.

For the purposes of the experiment, the tip scans an area under constant bias voltage, higher than the threshold value. Two parameters are simultaneously stored: the variations of the tip $z$-position yielding the surface topography under constant tunnel current mode and the different values of collector current shown in grey levels which allow for a "BEEM image" of the interface to be built up (see Fig. 1). As the BEEM experiments on Si (Réfs. [2-4] [19,20]) always provide a large range of contrasts, a scanned area $160 \mathrm{~nm} \times 160 \mathrm{~nm}$ is chosen, so as to obtain a large statistical distribution of collector current intensities. Scanning velocity is about $64 \mathrm{~nm} \cdot \mathrm{s}^{-1}$ To get a significant BEEM current (a few tens of the pA range), the tunnel current varies from $2 \mathrm{nA}$ to $20 \mathrm{nA}$. For each sample, the bias voltage ranges from $1 \mathrm{~V}$ to $2 \mathrm{~V}$, in steps of $0.1 \mathrm{~V}$. The minimum value is chosen higher than $0.8 \mathrm{~V}$, owing to the Schottky Barrier Height (SBH) usually observed on Au-Si contacts (between $0.77 \mathrm{eV} \mathrm{[19]} \mathrm{and} 0.8 \mathrm{eV}$ [21]).

For the samples, $\mathrm{n}$-Si (P-doped at $10^{19} \mathrm{~cm}^{-3}$ ) substrates covered by an $11 \mu \mathrm{m}$-Si-epitaxial layer, P-doped at $10^{15} \mathrm{~cm}^{-3}$, have been used. Following chemical cleaning in a (HF:methanol, 1:4) solution, a $150 \mathrm{~nm}$ thick gold layer is evaporated on the rear side of the Si wafer. Heating at $300^{\circ} \mathrm{C}$ for five minutes provides a good interdiffusion between $\mathrm{Au}$ and $\mathrm{Si}$, thus resulting in a low resistance ohmic contact. After renewed chemical cleaning, a final gold deposition is carried out on the front side of Si, under Ultra Hight Vacuum $\left(10^{-8}\right.$ Torr $)$, through a mask with $0.5 \mathrm{~mm}$-diameter holes, a small diameter being required to avoid excessive noise and leakage currents. Five different gold thicknesses have been selected: $7.5 \mathrm{~nm}, 9.5 \mathrm{~nm}, 14 \mathrm{~nm}, 18.8 \mathrm{~nm}$, and $24.5 \mathrm{~nm}$. The thickness of gold evaporated is given by a quartz crystal microbalance which accuracy $( \pm 10 \%)$ has previously been controlled by Atomic Force Microscopy measurements on thin gold films (typically $10 \mathrm{~nm}$ ) deposited on flat graphite surfaces. The metal layer appear to be polycrystalline, presenting the same roughness, between $3 \mathrm{~nm}$ and $4 \mathrm{~nm}$, for every thickness of gold. Finally, a $50 \mu \mathrm{m}$-diameter copper wire is bonded to the Au film, so as to obtain the required bias voltage. Using this process, the macroscopic $I(V)$ spectra of each diode are characterized by ideality factors $n$ in the 1-1.1 range. All tips are Pt-Ir, and obtained by cutting a 0.25 mm-diameter Pt-Ir wire. Figure 2 schematically depicts BEEM experiment.

\section{Results}

As the aim is to study the electron transport through the gold layer, STM topographies are only used to test the tip quality. Then, if the tip gives the characteristic gold grains with a good reliability (Fig. 1a), the BEEM image (Fig. 1b), acquired simultaneously, is processed to obtain the histogram of the collected current. 


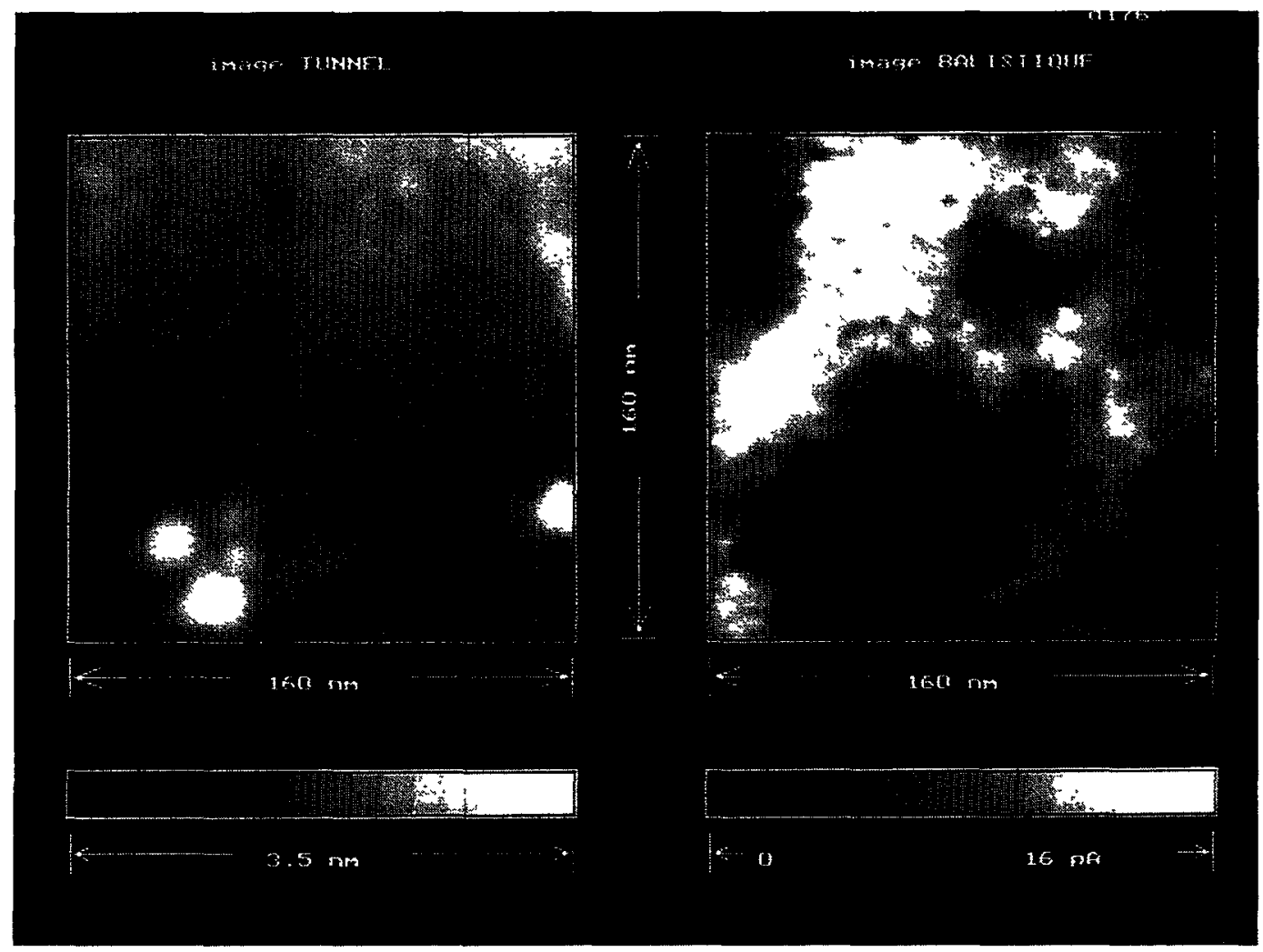

a)

b)

Fig. 1. - a) STM image of the metal layer. Scan size is $160 \mathrm{~nm} \times 160 \mathrm{~nm} . I_{t}=6 \mathrm{nA}, V_{t}=1.3 \mathrm{~V}$, gold thickness $=9.5 \mathrm{~nm}, \Delta z=3.5 \mathrm{~nm}$. b) BEEM image. The maximum contrast corresponds to collector current variations of $16 \mathrm{pA}$.

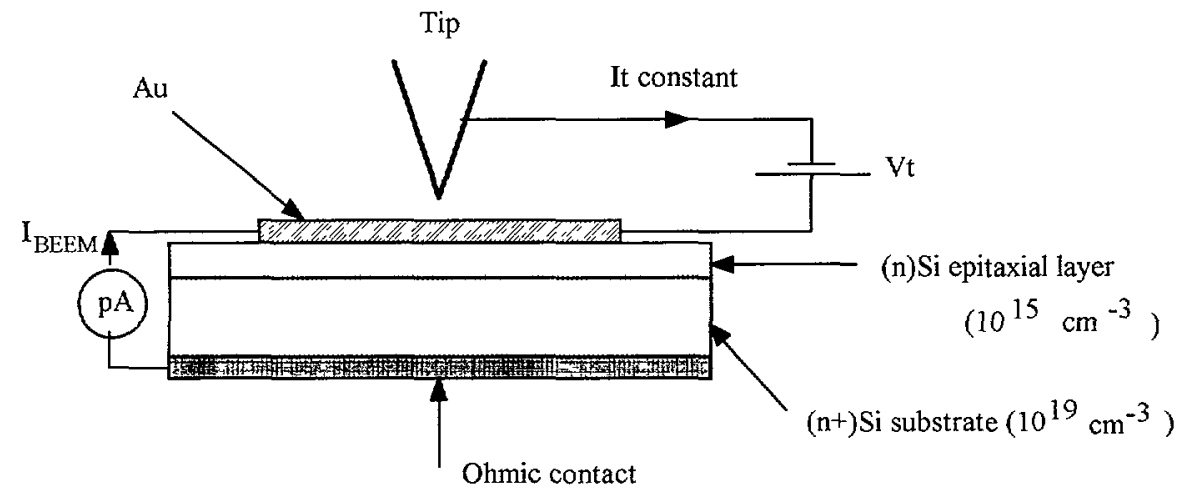

Fig. 2. - Schematic diagram of the experimental set-up. For spectra acquisition, $V_{\mathrm{t}}$ varies from $0.5 \mathrm{~V}$ to $2.5 \mathrm{~V}$ and the tip remains fixed. For BEEM imaging, $V_{\mathrm{t}}$ is kept constant while the tip scans the Au area. A feedback loop fixes the value of $I_{t}$, while an electronic set-up records the variations of BEEM current. 


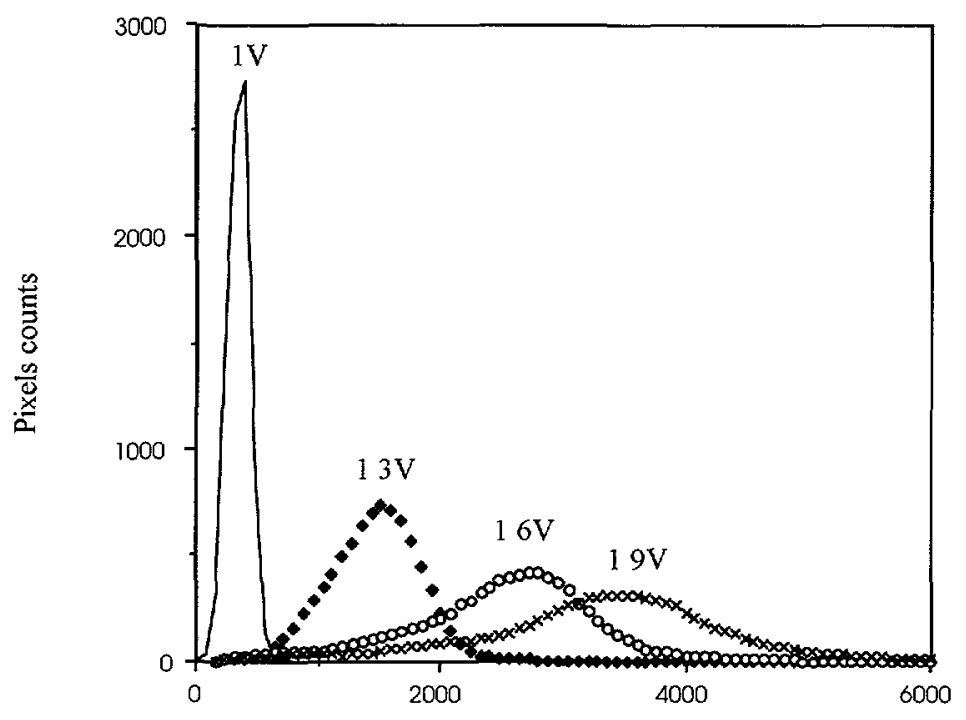

Collector current intensities in $\mathrm{fA}$

Fig. 3. - Histograms of BEEM images from a $9.5 \mathrm{~nm}$-thick gold film at four different bias voltages: $1 \mathrm{~V}, 1.3 \mathrm{~V}, 1.6 \mathrm{~V}, 1.9 \mathrm{~V}$. Increase in the average collector current is clearly evidenced. Those curves present the following FWHM: $314 \mathrm{fA}$ for $1 \mathrm{~V}, 863 \mathrm{fA}$ for $1.3 \mathrm{~V}, 1201 \mathrm{fA}$ for $1.6 \mathrm{~V}, 1365 \mathrm{fA}$ for $1.9 \mathrm{~V}$.

Table I. - Average values of $I_{\mathrm{c}}$ in $n A$, for each sample when $V_{\mathrm{t}}$ increases from $1 V$ to $1.8 \mathrm{~V}$. Thicknesses of gold, $d$, are given in $n m$.

\begin{tabular}{|c|c|c|c|c|c|c|c|c|c|}
\cline { 2 - 11 } \multicolumn{1}{c|}{} & \multicolumn{10}{|c|}{$V_{\mathrm{t}}(\mathrm{V})$} \\
\hline$d(\mathrm{~nm})$ & 1 & 1.1 & 1.2 & 1.3 & 1.4 & 1.5 & 1.6 & 1.7 & 1.8 \\
\hline 7.5 & 0.449 & 0.866 & 1.38 & 1.68 & 2.275 & 2.716 & 3.257 & 3.527 & - \\
\hline 9.5 & 0.349 & 0.577 & 0.942 & 1.457 & 1.597 & 2.373 & 2.504 & 2.768 & 3.317 \\
\hline 14 & 0.285 & 0.514 & 0.941 & 1.139 & 1.513 & 1.691 & 1.92 & 1.97 & 2.463 \\
\hline 18.8 & 0.168 & 0.277 & 0.416 & 0.572 & 0.599 & 0.859 & 1.045 & 1.095 & 1.208 \\
\hline 24.5 & 0.09 & 0.116 & 0.214 & 0.398 & 0.325 & 0.548 & 0.693 & 0.62 & 0.731 \\
\hline
\end{tabular}

The evolution, in terms of bias voltage, of these histograms for the $9.5 \mathrm{~nm}$-thick sample is shown in Figure 3. The increase of the average collector current is clearly evidenced from $1 \mathrm{~V}$ to $1.9 \mathrm{~V}$. The Full Width at Half Maximum (FWHM) of each curve also increases with voltage mainly because of the broad energy distribution of the injected electrons at high voltages. However, providing the scanned area is large enough (a constant size of $160 \mathrm{~nm} \times 160 \mathrm{~nm}$ is used), the average value of the injected current, computed for each histogram and normalized to an injected current of $1 \mathrm{nA}$, may be related to the transmission rate $T$ for the mean gold thickness $d$.

Table I indicates the variations of the average current in terms of bias voltage for the five samples. These variations are also given in Figure 4. Furthermore, two features have to be taken into account. On the one hand, high surface corrugations may give large BEEM 


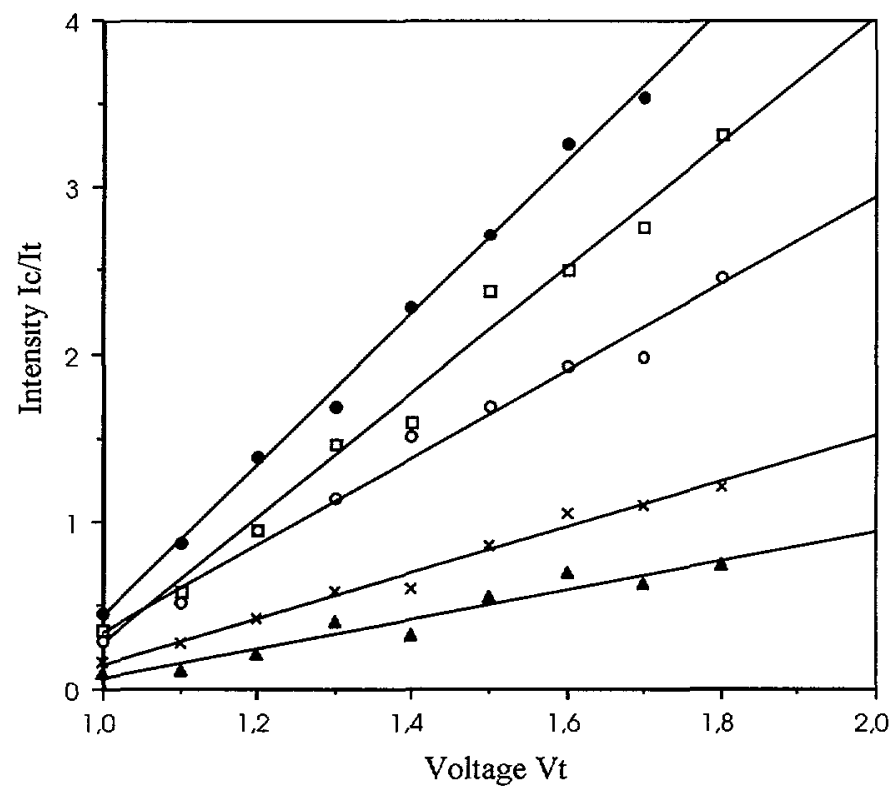

Fig. 4. - Variations of the normalized induced current $\left(I_{\mathrm{c}} / I_{\mathrm{t}}\right)$ in terms of bias voltage for the five

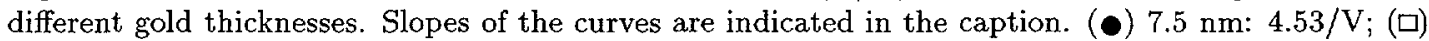
$9.5 \mathrm{~nm}: 3.74 / \mathrm{V}$; (O) $14 \mathrm{~nm}: 2.59 / \mathrm{V}$; (×) $18.8 \mathrm{~nm}: 1.36 / \mathrm{V}$; (A) $24.5 \mathrm{~nm}: 0.86 / \mathrm{V}$.

intensities. On the other hand, the maximum surface corrugation is almost constant (between $3 \mathrm{~nm}$ and $4 \mathrm{~nm}$ ) as soon as the evaporated gold thickness exceeds $5 \mathrm{~nm}$. Then, the collector current magnitude is weakly related to the surface roughness. Consequently, association of the transmission coefficient with the island structure is lost in the histograms and then, in Figure 4. The general trend of a film thickness effect is preserved.

For each thickness, the mean current is found to be linearly dependent on the bias voltage (Fig. 4), which suggests that the transmission rate is constant in this energy range. Previous theoretical studies have demonstrated that near the threshold $V_{\mathrm{b}}$, power laws $\left(V-V_{\mathrm{b}}\right)^{\alpha}$, with $\alpha$ varying from 0.5 to $5 / 2$, may be used to fit the BEEM spectroscopic data [12]. However, these different calculations and, especially, the experimental data, show that beyond the threshold region, the variations of $I_{\mathrm{BEEM}}(V)$ are linear [22]. Beyond $2 \mathrm{~V}$, the effects of inelastic diffusion lead to a small decrease of the spectrum slope (i.e., $\alpha$ decreases). In the $1 \mathrm{~V}-2 \mathrm{~V}$ range, a linear fit for the data of Figure 4 therefore seems reasonable.

The transmission rate variations in terms of metal thickness are given in Figures 5a (linear scale) and $5 \mathrm{~b}$ (semi-logarithmic scale) and may be fitted using the well-known equation:

$$
T=T_{0} e^{-d / \lambda}
$$

where $\lambda$ is the electron mean free path and $d$ the average gold thickness. Using this formula and Figures $5 \mathrm{a}$ and $\mathrm{b}$, a value of $\lambda=10 \mathrm{~nm} \pm 0.2 \mathrm{~nm}$ has been calculated. 
Transmission rate $(N)$

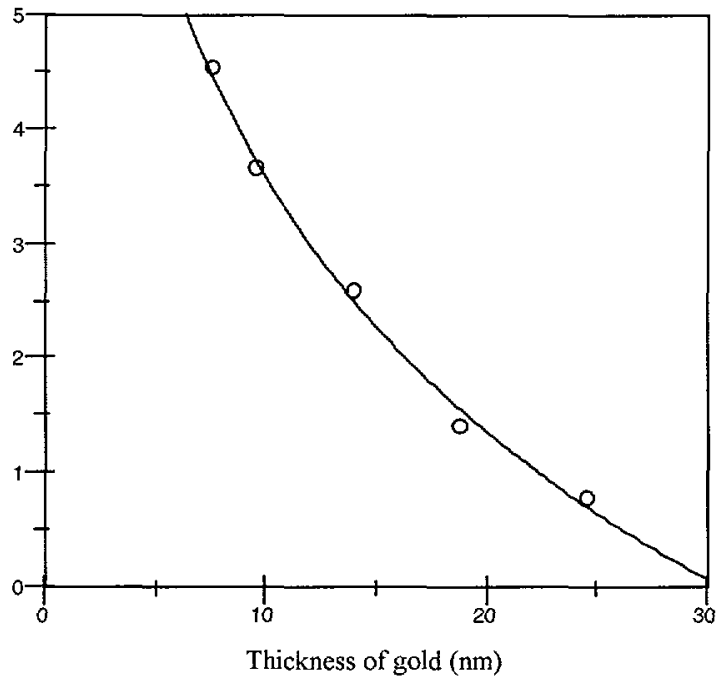

a)

$\ln (\mathrm{T})$

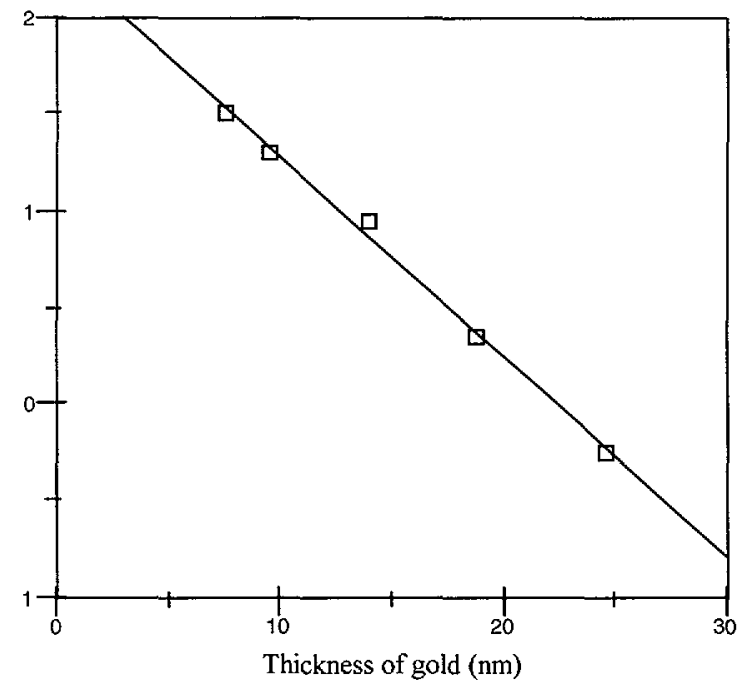

Fig. 5. - a) Transmission rate in terms of gold thickness (linear scale). b) Same curve with a semilogarithmic scale. The slopes of the curve gives: $\lambda=10 \mathrm{~nm}$.

\section{Discussion}

This result is in good agreement with previous values of $\lambda$ ranging from $10 \mathrm{~nm}$ to $20 \mathrm{~nm}[22,23]$. As this value is also constant in this energy range (Fig. 4), $\lambda$ is assumed to be due to elastic scattering in the metal, because, unlike the inelastic one, the elastic mean free path is not energy-dependent. 
In previous papers, Palm et al. used the same experimental method to investigate the electron mean free path in the gold layer of an $\mathrm{Au} / \mathrm{n}$-Si(111) contact [22]. These authors found a value of $\lambda=14 \mathrm{~nm}$ for a constant voltage below $1.2 \mathrm{~V}$ but did not investigate its variations in terms of bias voltage. Also, Niedermann et al. evaluated $\lambda$ in a $\mathrm{PtSi} / \mathrm{n}-\mathrm{Si}(100)$ Schottky diode and considered the two values observed $(1.4 \mathrm{~nm}$ and $7.6 \mathrm{~nm}$ ) as resulting from a bilayer structure in the metal film [24].

Our experiment suggests that this bilayer structure is not present in the Au/Si junction or that it extends to a lesser scale (e.g. less than $1 \mathrm{~nm}$ at the interface) and does not significantly modify electron transport. The interface is then assumed to be abrupt and experiments are performed a few days after film deposition to prevent any Au/Si interdiffusion at the interface. The contrast observed in the $\mathrm{Au} / \mathrm{Si}$ contacts as well as in other metal/semiconductor junctions $[25,26]$ cannot be explained by thickness variations of the metal layer because adjacent grains (i.e. with same corrugations) may give completely different contrasts. Palm et al. [22] also show that the comparison of the transmission and corrugation histograms indicates a negligible role of the thickness variations in the transmission coefficient.

As the gold layer is polycrystalline, a variation of $\lambda$ with the crystallographic orientation of each grain seems more appropriate to account for these different BEEM contrasts. The mean value of $\lambda$ is $10 \mathrm{~nm}$, but this value may be slightly different for each grain. Indeed, the determination of $\lambda$ by the preceeding method averages the local value that may differ from one grain to another. For example, by using a Monte-Carlo simulation (with parameters identical to those proposed by Bauer et al. $[8,27]$ or Schowalter and Lee [23]) and by decreasing the elastic mean free path from $10 \mathrm{~nm}$ to $7.5 \mathrm{~nm}$ (i.e., channeling), the collector current increases by $20 \%$. As $\lambda$ appears as a relevant parameter in the simulation of the BEEM contrasts, experiments are in hand to calculate the "local" elastic mean free path by studying the BEEM current variations on individual gold grains.

\section{Conclusions}

By processing the BEEM image, the electron mean free path has been calculated for electron energies in the $1 \mathrm{eV}$ to $2 \mathrm{eV}$ range. A constant value of $10 \mathrm{~nm}$ has been obtained and may be considered as an average value of all the possible surface orientations. Its behaviour is in good agreement with an elastic scattering phenomenon which is known to be rather independent of the electron energy above the Fermi level. This result is particularly interesting for MonteCarlo calculations near the threshold voltage given the important role of diffusion transport in BEEM experiments.

\section{Acknowledgments}

The authors would like to thank G. Peuch for technical assistance and P. Bourseau for Si preparation.

\section{References}

[1] Binnig G., Rohrer H., Gerber Ch. and Weibel E., Tunneling through a controllable vacuum gap, Appl. Phys. Lett. 40 (1982) 178.

[2] Bell L.D., Kaiser W.J., Hecht M.H. and Grunthaner F.J., Direct control and characterization of a Schottky barrier by Scanning Tunneling Microscopy, Appl. Phys. Lett. 52 (1988) 278. 
[3] Kaiser W.J. and Bell L.D., Direct investigation of subsurface interface electronic structure by Ballistic Electron Emission Microscopy, Phys. Rev. Lett. 60 (1988) 1406.

[4] Bell L.D. and Kaiser W.J., Observation of interface band structure by Ballistic Electron Emission Microscopy, Phys. Rev. Lett. 61 (1988) 2368.

[5] Talin A.A., Ohlberg D.A.A., Williams R.S., Sullivan P., Koutselas I., Williams B. and Kavanagh K.L., Time dependent Ballistic Electron Emission Microscopy studies of a $\mathrm{Au} /(100) \mathrm{GaAs}$ interface with a native oxide diffusion barrier, Appl. Phys. Lett. 62 (1993) 2965.

[6] Talin A.A., Williams R.S., Morgan B.A., Ring K.M. and Kavanagh K.L., Nanometerresolved spatial variations in the Schottky barrier height of a $\mathrm{Au} / \mathrm{n}$-type GaAs diode, Phys. Rev. B 49 (1994) 16474.

[7] Ludeke R. and Prietsch M., Ballistic Electron Emission Spectroscopy of noble metalGaP(110) interfaces, J. Vac. Sci. Technol. A 9 (1991) 885.

[8] Bauer A., Cuberes M.T., Prietsch M. and Kaindl G., Ballistic Electron Emission Microscopy at metal/GaP(110) interfaces: electron transport and Schottky-barrier heights, J. Vac. Sci. Technol. 11 (1993) 1584.

[9] Williams R.H., Ballistic Electron Emission Microscopy of metal/semiconductor interfaces and heterojunctions, Appl. Surf. Sci. 70 (1993) 386.

[10] Fowell A.E., Williams R.H., Richardson B.E. and Shen T.H., The Au/CdTe interface: an investigation of electrical barriers by Ballistic Electron Emission Microscopy, Semicond. Sci. Technol. 5 (1990) 348.

[11] Coratger R., Ajustron F., Beauvillain J., Dharmadasa I.M., Blomfield C.J., Prior K.A., Simpson J. and Cavenett B.C., Au/n-ZnSe contacts studied with use of Ballistic Electron Emission Microscopy, Phys. Rev. B 51 (1995) 2357.

[12] Henderson G.N., First P.N., Gaylord T.K. and Glytsis E.N., Quantum transmittance from low-temperature Ballistic Electron Emission Spectroscopy of $\mathrm{Au} / \mathrm{Si}(100)$ Schottky interfaces, Phys. Rev. Lett. 71 (1993) 2999.

[13] Cuberes M.T., Bauer A., Wen H.J., Vandré D., Prietsch M. and Kaindl G., Ballistic Electron Emission Microscopy on the Au/n-Si(111) $7^{*} 7$ interface, J. Vac. Sci. Technol. B 12 (1994) 2422.

[14] Bell L.D., Hecht M.H., Kaiser W.J. and Davis L.C., Direct Spectroscopy of electron and hole scattering, Phys. Rev. Lett. 64 (1990) 2679.

[15] Lee E.Y. and Schowalter L.J., Phonon scattering and quantum mechanical reflection at the Schottky barrier, J. Appl. Phys. 70 (1991) 2156.

[16] Bell L.D., Manion S.J., Hecht M.H., Kaiser W.J., Fathauer R.W. and Milliken A.M., Characterizing hot-carrier transport in silicon heterostructures with the use of Ballistic Electron Emission Microscopy, Phys. Rev. B 48 (1993) 5712.

[17] Bauer A. and Ludeke R., Direct determination of impact ionization quantum yield in Si by Ballistic Electron Emission Microscopy, Phys. Rev. Lett. 72 (1994) 928.

[18] Coratger R., Beauvillain J., Ajustron F., Lacaze J.C. and Tremollieres C., A stage for submicron displacements using electromagnetic coils and its application to Scanning Tunneling Microscopy, Rev. Sci. Instrum. 62 (1991) 830.

[19] Coratger R., Ajustron F. and Beauvillain J., Ballistic Electron Emission Microscopy of the Au-Si(100) interface, J. Phys. III France 3 (1993) 2211.

[20] Coratger R., Ajustron F. and Beauvillain J., Characterization of the metal-semiconductor interface by Ballistic Electron Emission Microscopy, Microsc. Microanal. Microstruct. 5 (1994) 31.

[21] Palm H., Arbes M. and Schulz M., Fluctuations of the Au-Si(100) Schottky barrier height, Phys. Rev. Lett. 71 (1993) 2224. 
[22] Palm H., Arbes M. and Schulz M., Nanometer microscopy of the electron transmission through an ultrathin ( $3-22 \mathrm{~nm}$ ) Au film and of the Au-Si Schottky barrier height, Appl. Phys. A 56 (1993) 1.

[23] Schowalter L.J. and Lee E.Y., Role of elastic scattering in Ballistic Electron Emission Microscopy of $\mathrm{Au} / \mathrm{Si}(100)$ and $\mathrm{Au} / \mathrm{Si}(111)$ interfaces, Phys. Rev. B 43 (1991) 9308.

[24] Niedermann P., Quattropani L., Solt K., Kent A.D. and Fisher O., Ballistic Electron Emission Microscopy study of PtSi-n-Si(100) Schottky diodes, J. Vac. Sci. Technol. B 10 (1992) 580.

[25] Hecht M.H., Bell L.D., Kaiser W.J. and Grunthaner F.J., Ballistic Electron Emission Microscopy investigation of Schottky barrier interface formation, Appl. Phys. Lett. 55 (1989) 780.

[26] Niedermann P., Quattropani L., Solt K., Maggio-Aprile I. and Fisher O., Hot-carrier scattering in a metal: a Ballistic Electron Emission Microscopy investigation on $\mathrm{PtSi}$, Phys. Rev. B 48 (1993) 8833.

[27] Bauer A., Cuberes M.T., Prietsch M. and Kaindl G., Quantitative study of electron transport in Ballistic Electron Emission Microscopy, Phys. Rev. Lett. 71 (1993) 149. 